\title{
Effects of Intracerebroventricular Micro-injection of Kaempferol on Anxiety: Possible GABAergic Mechanism Involved
}

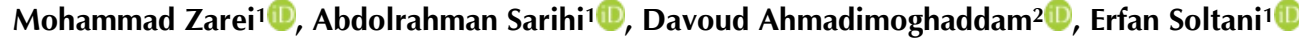 \\ 1 Department of Physiology, Neurophysiology Research Center, Faculty of Medicine, Hamadan University of \\ Medical Sciences, Hamadan, Iran \\ 2 Department of Pharmacology and Toxicology, Faculty of Pharmacy, Hamadan University of Medical \\ Sciences, Hamadan, Iran
}

\author{
*Corresponding author: \\ Mohammad Zarei, Department of \\ Physiology, Neurophysiology \\ Research Center, Faculty of Medicine, \\ Hamadan University of Medical \\ Sciences, Hamadan, Iran \\ Tel: +988138380490 \\ Email: zarei@umsha.ac.ir
}

Received: 07 Aug. 2020 Accepted: 14 Sep. 2020 ePublished: 01 May. 2021

\begin{abstract}
Background and Objective: Kaempferol (KM) is one of the most important plants with neuroprotection and analgesic effects. In addition, bicuculline (BIC) is a competitive antagonist of the $\mathrm{GABA}_{\mathrm{A}}$ ionotropic receptor (the most important targets of benzodiazepines and other anxiety suppressants). In this study, intracerebroventricular microinjection of KM on anxiety and its interaction with GABAergic mechanism were investigated in male rats.

Materials and Methods: In this exploratory investigation, the male rats were divided into the following groups: control (saline), groups treated by KM (0.5 and $2 \mu \mathrm{g} / \mathrm{rat}), \mathrm{DMSO}(1 \mu \mathrm{g} / \mathrm{rat}), \mathrm{KM}$ $0.5+\mathrm{BIC} 1 \mu \mathrm{g} / \mathrm{rat}, \mathrm{KM} 0.5+\mathrm{BIC} 4 \mu \mathrm{g} / \mathrm{rat}$, KM 2+BIC1 $\mu \mathrm{g} / \mathrm{rat}$, BIC groups $(1,4 \mu \mathrm{g} / \mathrm{rat})$, and KM 2+BIC 4 $\mu \mathrm{g} / \mathrm{rat}$. Besides, an elevated plus-maze paradigm was used for the evaluation of the anxiety.

Results: Statistical analysis revealed that the indices of TTOA in KM groups (0.5 and $2 \mu \mathrm{g} / \mathrm{rat})$ significantly increased in comparison to the control group $(\mathrm{P}<0.05$ and $\mathrm{P}<0.01$, respectively). Moreover, regarding the involvement of the GABAergic system in the anxiolytic-like activity of KM, it was demonstrated that the TTOA related to Co-administration of KM $(0.5 \mu \mathrm{g} / \mathrm{rat})$ with bicuculline $(1 \mu \mathrm{g} / \mathrm{rat})$ significantly reduced, compared to the control group $(\mathrm{P}<0.05)$.

Conclusions: According to the obtained results, the use of KM can likely improve anxiety through GABAergic mechanism(s).

Keywords: Anxiety, Bicuculline, GABAergic mechanism, Kaempferol
\end{abstract}

\section{Background}

Today, anxiety is an overwhelming condition that is broadly associated with various disorders in the community. It is presumed that 26.9 million persons in the USA have anxiety syndromes (AS). Moreover, about $5-30 \%$ of people around the world are affected by AS during their lifetime. Predominant attainable of effective, comparatively low rate outpatient management may significantly lessen the economic and aggregate load of these common and habitually devastating disorders [1]. Presented in 1980, benzodiazepines immediately became the most generally utilized psychotropic medications. However, currently, perspectives toward these chemical compounds have extremely changed, and the development of awareness and concern about dependence risk, withdrawal marvels, and side effects have called the usage of these compounds into question [2].

The $\mathrm{GABA}_{\mathrm{A}}$ receptors $(\boldsymbol{\gamma}$-Aminobutyric acid type A) are prime control elements (on the molecular levels) in light of the fact that benzodiazepines-site ligands can therapeutically attenuate anxiety. Moreover, a deficit of $\mathrm{GABA}_{\mathrm{A}}$ receptors has been recognized in the different areas of the brain in patients experiencing panic attacks. A $G_{A B A}$ receptors deficit has likewise been ensnared in summed up anxiety disorders [3].

Bicuculline $\left(\mathrm{C}_{2} \mathrm{OH}_{17} \mathrm{NO}_{6}\right)$ is a phthalate-isoquinoline compound that can be extracted from plants, such as Dicentra cucullaria and Adlumia fungosa. Bicuculline (BIC) has also been a competitive antagonist of the $\mathrm{GABA}_{\mathrm{A}}$ ionotropic receptor. These receptors are also the most important targets of benzodiazepines and other anxiety suppressants [4, 5].

The flavonoid of Kaempferol (KM) (molecular formula: $\mathrm{C}_{15} \mathrm{H}_{10} \mathrm{O}_{6}$ ) is found in numerous palatable plants (e.g., tomato and grapes) or floral products frequently utilized in conventional medicine (e.g., Hedera belix and Erigeron acer) [6-8]. Some basic examinations found a positive relationship between the utilization of nourishments containing $\mathrm{KM}$ and a diminished risk of developing a few disorders, such as cardiovascular and neurological diseases. Various pre-clinical investigations indicated that $\mathrm{KM}$ as well as its glycosides have a wide range of pharmacological effects, such as anti-diabetic, 
anti-microbial, anti-osteoporotic, and analgesic effects [9-13]. The evidence has shown that kaempferol can act as a ligand for various receptors, such as GABAergic and cholinergic receptors [13-15].

To the best of our knowledge, no investigations have been performed on the intracerebroventricular microinjection of $\mathrm{KM}$ on anxiety through the $\mathrm{GABA}_{\mathrm{A}}$ mechanism.

\section{Objectives}

The present study aimed to examine the anti-anxiety effects of $\mathrm{KM}$ and its interaction with $\mathrm{GABA}_{\mathrm{A}}$ receptors using one of the most important validated paradigms to assess anxiety (elevated plus-maze test) in male rats.

\section{Materials and Methods}

Experimental animals

Male rodents (Wistar race rats; weighing 220-250 g) were obtained from the neurophysiology research center (animal house sub-group) of Hamadan University of Medical Sciences, Iran. All male rats were permitted to adjust to the research center conditions for about one-week for five $\mathrm{min} / \mathrm{day}$ before the procedure. The rodents were kept in special boxes at standard temperature $\left(22 \pm 2^{\circ} \mathrm{C}\right)$ with a $12 / 12 \mathrm{~h}$ dark/light cycle. The adult rats were free to use food (Pellet) or water (eight male adult rats in each laboratory group).

The present research was approved by the Ethics Committee of the Hamadan University of Medical Sciences (code: IR. UMSHA. REC. 1397. 728). In this study, the following groups (10 groups) were used ( $\mathrm{n}=8$ rats in each group): control, DMSO, KM $0.5 \mu \mathrm{g} /$ rat, KM $2 \mu \mathrm{g} /$ rat, KM $0.5 \mu \mathrm{g} /$ rat +BIC 1 $\mu \mathrm{g} / \mathrm{rat}, \mathrm{KM} 0.5 \mu \mathrm{g} / \mathrm{rat}+\mathrm{BIC} 4 \mu \mathrm{g} / \mathrm{rat}, \mathrm{KM} 2$ $\mu \mathrm{g} /$ rat $+\mathrm{BIC} 1 \mu \mathrm{g} /$ rat, KM $2 \mu \mathrm{g} /$ rat $+\mathrm{BIC} 4$ $\mu \mathrm{g} /$ rat, BIC $1 \mu \mathrm{g} /$ rat, BIC $4 \mu \mathrm{g} /$ rat.

\section{Medications}

Kaempferol and bicuculline were bought from Sigma-Aldrich Company, USA. Dimethyl sulfoxide or DMSO were utilized for dissolving $\mathrm{KM}$ and $\mathrm{BIC}$ 20 min before intracerebroventricular micro-injection (ICVM). The KM $(0.5,2 \mu \mathrm{g} /$ rat $)$ and bicuculline $(1,4$ $\mu \mathrm{g} / \mathrm{rat})$ dosages were chosen depending on recently distributed examinations $[13,16]$.

\section{Surgery procedure and infusion of the medications}

The surgical procedure started by co-administration of ketamine-xylazine (with the proportion of 50 $\mathrm{mg} / \mathrm{kg}+5 \mathrm{mg} / \mathrm{kg}$, respectively) for the production of anesthesia [17,18]. The 22-gauge tube (guide cannulas) was inserted one $\mathrm{mm}$ above the injection site (lateral ventricles [LV]) based on the rat brain atlas by Paxinos and Watson, bilaterally (both left and right hemisphere) [19]. The $50 \mu$ l Hamilton syringe connected to polyethylene (PE) tubing was utilized for the administration of KM or BIC. It must be mentioned that the infusion took 3-4 min.

Coordinates of the rodent brain

For this purpose, a single administration was used in the LV as follows: $0.8 \mathrm{~mm}$ posterior to the bregma, $\pm 1.4 \mathrm{~mm}$ lateral to the sagittal suture, and $3.4 \mathrm{~mm}$ from the top of the skull $[20,21]$.

\section{Elevated plus maze}

This technique is essentially the same as the one described by Shahidi et. al [22, 23]. The elevated plus maze (EPM) consists of four arms (a wooden cross-shaped maze) and looks like a plus sign. There were two open arms as well as two closed arms in the EPM and it was elevated $50 \mathrm{~cm}$. The effects of ICVM of the medications were examined in the EPM five days after cannulation. The rodents were independently positioned in the focal point of the EPM (confronting an open arm) and permitted five min of free investigation. The total time spent in the open arms (TTOA) and the number of entries into the open arms (NEOA) were determined by videotaped records.

\section{Statistical analysis}

The GraphPad Prism (Version 6) was utilized for the analysis of the significant differences among groups. Moreover, the data were scanned by ordinary one-way ANOVA and Bonferroni posthoc test. All the results were presented as means \pm SEM and a p-value of less than 0.05 was considered statistically significant.

Results

According to Figure 1.A., the results of the one-way ANOVA regarding TTOA reflect the significant differences between the groups $[\mathrm{F}(3,28)=92.4$, $\mathrm{P}<0.001]$. Further analysis using Bonferroni posttest revealed significant changes in the TTOA after injection of 0.5 and $2 \mu \mathrm{g} /$ rat doses of $\mathrm{KM}$, compared to the vehicle control group $(\mathrm{P}<0.05$, $\mathrm{P}<0.001$, respectively).

According to Figure 1.B., results of the one-way ANOVA regarding T'TOA revealed a significant difference between the groups $[\mathrm{F}(7,56)=24.8, \mathrm{P}<$ 0.001]. Further analysis using Bonferroni post-test showed that the T'TOA after co-injection of KM $(0.5 \mu \mathrm{g} / \mathrm{rat})$ and BIC (4 $\mu \mathrm{g} / \mathrm{rat})$ reduced, compared to the vehicle control group $(\mathrm{P}<0.01)$. Moreover, there were significant differences between BIC with 

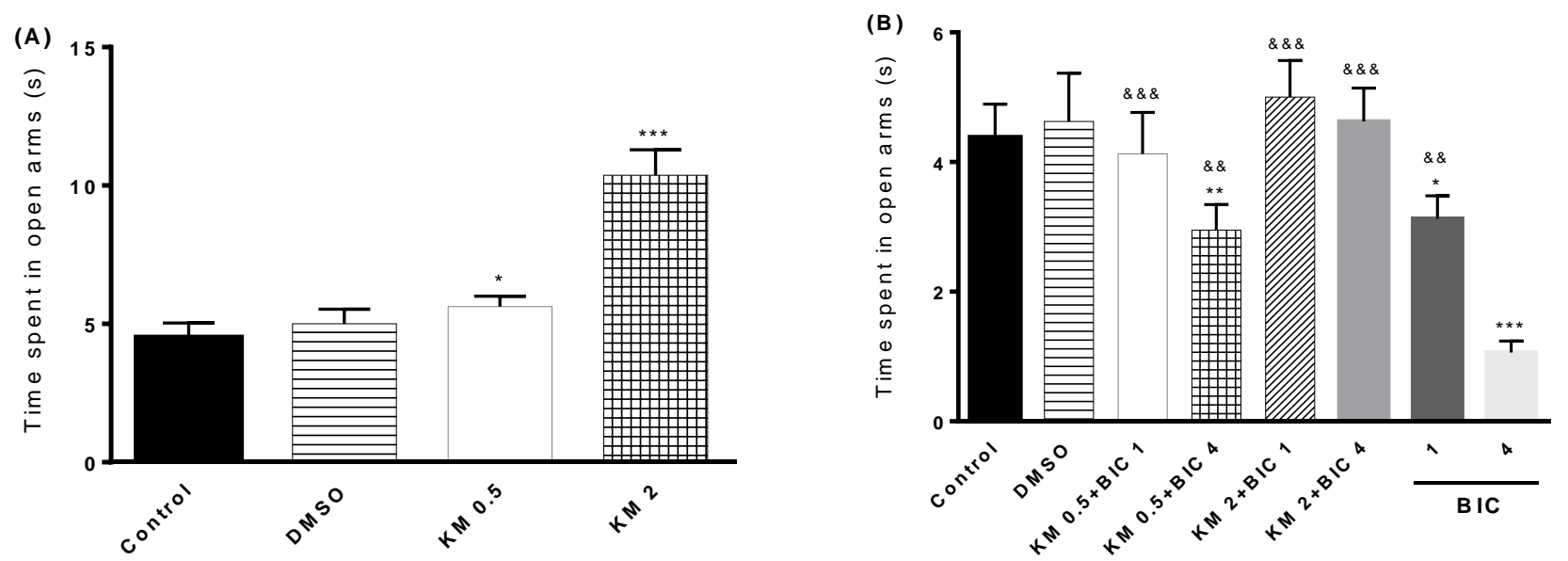

Figure 1. Effect of intracerebroventricular injection of 0.5 and $2 \mu \mathrm{g} / \mathrm{rat}$ of kaempferol $(\mathrm{KM})$ on the TTOA (A) and its interaction with GABA mechanism (b) in male rats.

DMSO: dimethyl sulfoxide, BIC: bicuculline $\left(1,4 \mu \mathrm{g} / \mathrm{rat}\right.$, an antagonist of $\mathrm{GABA}_{\mathrm{A}}$ receptors). The data are expressed as mean $\pm \mathrm{SEM}$.

*: $\mathrm{P}<0.05,{ }^{* *}: \mathrm{P}<0.01,{ }^{* * *}: \mathrm{P}<0.001$ vs. control group

\&\&: $\mathrm{P}<0.01$, \&\&: $\mathrm{P}<0.001$ vs. BIC: $4 \mu \mathrm{g} / \mathrm{rat}(\mathrm{n}=8$ in each group)

doses of 1 and $4 \mu \mathrm{g} /$ rat compared to the vehicle control group $(\mathrm{P}<0.05, \mathrm{P}<0.001$, respectively). In addition, the results of the co-administration of $\mathrm{KM}(2 \mu \mathrm{g} / \mathrm{rat}))$ and $\mathrm{BIC}(4 \mu \mathrm{g} / \mathrm{rat})$ were significantly different from those of BIC $(4 \mu \mathrm{g} / \mathrm{rat})$ $(\mathrm{P}<0.001)$.

According to Figure 2.A., one-way ANOVA analysis of the number of entries into the open arm revealed significant differences between the groups $[\mathrm{F}(3,16)=63.87, \mathrm{P}<0.001]$. Further analysis using Bonferroni post-test exhibited significant changes in the number of entries into the open arm after injection of 0.5 and $2 \mu \mathrm{g} / \mathrm{rat}$ doses of $\mathrm{KM}$, compared to the vehicle control group $(\mathrm{P}<0.05$, $\mathbf{P}<0.001$, respectively).

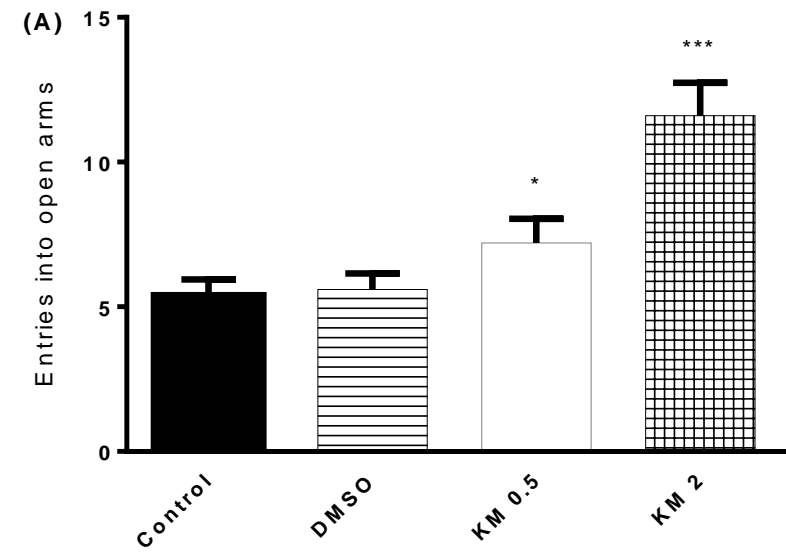

According to Figure 1.B., one-way ANOVA of the number of entries into the open arm points out the significant difference between the groups $[\mathrm{F}$ $(7,56)=37.22, \mathrm{P}<0.001]$. Further analysis using Bonferroni post-test revealed that the number of entries into the open arm after co-injection of $\mathrm{KM}$ $(2 \mu \mathrm{g} / \mathrm{rat})$ and BIC $(4 \mu \mathrm{g} / \mathrm{rat})$ reduced, compared to the vehicle control group $(\mathrm{P}<0.05)$. Moreover, there were significant differences between BIC with doses of 1 and $4 \mu \mathrm{g} / \mathrm{rat}$ compared to the vehicle control group ( $\mathrm{P}<0.01, \mathrm{P}<0.001$, respectively). In addition, results of the co-administration of $\mathrm{KM}(2 \mu \mathrm{g} / \mathrm{rat}))$ and BIC $(4 \mu \mathrm{g} / \mathrm{rat})$ were significantly different in comparison to those of the administration of BIC $(4 \mu \mathrm{g} / \mathrm{rat})(\mathrm{P}<0.001)$.

Figure 2. Effect of intracerebroventricular injection of 0.5 and $2 \mu \mathrm{g} /$ rat of kaempferol (KM) on the entries into the open arms (A) and its interaction with $\mathrm{GABA}_{\mathrm{A}}$ mechanism (b) in male rats.

DMSO: dimethyl sulfoxide, BIC: bicuculline $\left(1,4 \mu \mathrm{g} / \mathrm{rat}\right.$, an antagonist of $\mathrm{GABA}_{\mathrm{A}}$ receptors). The data are expressed as mean $\pm \mathrm{SEM}$

$*: \mathrm{P}<0.05,{ }^{* *}: \mathrm{P}<0.01, * * *: \mathrm{P}<0.001$ vs. control group

\&\&\&: $\mathrm{P}<0.001$, vs. BIC: $4 \mu \mathrm{g} / \mathrm{rat})(\mathrm{n}=8$ in each group) 


\section{Discussion}

Based on the findings of this study, it can be said that intracerebroventricular microinjection of kaempferol in male rats decreases the level of experimental anxiety through the $\mathrm{GABA}_{\mathrm{A}}$ mechanism as measured by the TTOA and the NEOA of the EPM. Currently, the use of an EPM test for the evaluation of anti-anxiety medications is well established. In this test, the TTOA and the NEOA are used as indicators of anxiety [24].

According to the results of previous studies, it has been clearly shown that intrathecal injection of bicuculline (as an antagonist of $\mathrm{GABA}_{\mathrm{A}}$-type receptors) at a dose of $4 \mu \mathrm{g}$ reduced both the TTOA and the number of entries of female mice into the open arm [25]. Based on the findings of this study, the use of bicuculline at a dose of $4 \mu \mathrm{g}$ could reduce anxiety which is in line with those of the previous studies. Moreover, in the present study, the use of low dose bicuculline (1 $\mu \mathrm{g})$ was able to reduce the number of rat entries into the open arm; however, this is inconsistent with the results of previous studies in this regard. This difference could be due to the use of different routes of administration and/or dependent on the gender of rodents [26].

The results of numerous studies have confirmed the anxiolytic effect of flavonoids by intracerebroventricular injection in laboratory animals [27-29]. For example, the low-dose of flavonoid baicalein $(2 \mu \mathrm{g} / \mathrm{rat})$ has been shown to exert antianxiety effects when injected directly into the central nervous system due to its gabaergic mechanism, which is independent of the benzodiazepine sites. In the above-mentioned study, both indicators of anxiety, NEOA and T'TOA, increased in rats [30].

In this study, it was also found that the use of dehydroepiandrosterone sulfate as a GABA-A receptor antagonist could inhibit the anxiolytic effect of baicalein. The findings of this study also indicated that the use of low and high doses of KM as a flavonoid compound injected intraventricularly could increase both the NEOA and TTOA in male rats, which is inconsistent with those of previous studies. Moreover, it was found that the use of $\mathrm{GABA}_{\mathrm{A}}$ receptor antagonist (bicuculline), in a dosedependent manner, was able to reduce the anxiolytic effect of KM, which is in line with the findings of previous research. These results indicated the anti-anxiety effect of $\mathrm{KM}$ through interaction with the $\mathrm{GABA}_{\mathrm{A}}$ system.

Based on the results of a study conducted by Wolfman et al. in 1994, the administration of chrysin, as a flavonoid, could reduce anxiety through $\mathrm{GABA}_{\mathrm{A}}$ receptors. According to the aforementioned study, it is clearly demonstrated that microinjection of bicuculline reversed the antianxiety effects of chrysin [31]. This is in line with the results of the present study which indicated that the use of bicuculline altered the anti-anxiety effects of KM. Therefore, we proposed that the antianxiety effects of KM may be related to interaction with $\mathrm{GABA}_{\mathrm{A}}$ receptors.

Moreover, in the previous studies, it has been demonstrated that the anxiolytic activity of $\mathrm{KM}$ administrated through intraperitoneal injection was partially antagonized by concomitant administration of flumazenil (a benzodiazepine antagonist), but not by WAY-100635 (5-HT HA $_{1 \mathrm{~A}}$ receptor antagonist) [14]. In addition, in our laboratory, we have shown that the cholinergic system (methoctramine, a selective M2 receptor antagonist of acetylcholine) may be involved in improving the effect of KM on scopolamine-induced memory impairment [13]. Therefore, GABAaergic (neurons that produce GABA as their output) and cholinergic mechanism (s) could be involved, at least in part, in the anxiolytic activity of KM.

Studies have shown that overexpression of glyoxalase-1 (GLY) and glutathione reductase-1 (GRE) genes in the brains of rats increases anxietylike behaviors (through oxidative stress metabolism) [32]. Due to the fact that KM contains many antioxidants, like unsaturated fatty acids, it has probably exerted its anti-anxiety effect by inhibition of the GLY and GRE genes.

As previously said, flavonoids have been reported to have strong anti-anxiety effects as well as a wide range of pharmacological and biochemical functions. Flavonoids inhibit nitric oxide-mediated production as well as macrophage-induced nitric oxide-synthesizing enzyme mRNA expression in rats. It should also be noted that nitric oxide production also increases anxiety [33]. Therefore, in other words, the flavonoid KM may also inhibit anxiety through the nitric oxide pathway.

Flavonoids can exert their anti-anxiety effect by acting on benzodiazepine receptors attached to GABA receptors. In a study performed on Coriandrum sativum, it was found that the use of the extract of this plant due to its active constituents, $\mathrm{KM}$, could reduce anxiety through the gabaergic mechanism by binding to specific sites of benzodiazepines which is consistent with the results of the present study [29].

\section{Conclusions}

In summary, the results of the present study indicated that the intracerebroventricular microinjection of $\mathrm{KM}$ through interaction with $\mathrm{GABAA}_{-\mathrm{A}}$ receptors could possibly improve anxiety 
in male rats. The cellular and molecular investigation of the lesion in specific nuclei of the brain associated with anxiety, such as the amygdala and hypothalamus as well as the study of other pathways can help us to better understand the mechanisms of anxiety altered by KM.

\section{Compliance with ethical guidelines}

The present study was approved by the Ethics Committee of the Hamadan University of Medical Sciences (IR. UMSHA. REC. 1397. 728). Moreover, the tests and methodology were in accordance with the National Institutes of Health Guide for Care and Use of Laboratory Animals (1985, no 85-23).

\section{Authors' contributions}

All authors contributed equally to the preparation of this article.

\section{Funding/Support}

This study was financed by the Vice-Chancellor for Research and Technology, Hamadan University of Medical Sciences (No: 9706063368)

\section{Conflicts of Interest}

The authors declare that there was no conflict of interest in this study.

\section{References}

1. Hare BD, Duman RS. Prefrontal cortex circuits in depression and anxiety: contribution of discrete neuronal populations and target regions. Molecular Psychiatry. 2020; 25(11):2742-58. [DOI:10.1038/s41380-020-0685-9] [PMID] [PMCID]

2. Akter $\mathrm{S}$, Uddin KR, Sasaki $\mathrm{H}$, Lyu $\mathrm{Y}$, Shibata S. Gamma oryzanol impairs alcohol-induced anxiety-like behavior in mice via upregulation of central monoamines associated with Bdnf and II-1ß signaling. Scientific Reports. 2020; 10(1):10677. [DOI:10.1038/s41598-020-67689-w] [PMID] [PMCID]

3. Xiao Q, Zhou X, Wei P, Xie L, Han Y, Wang J, et al. A new GABAergic somatostatin projection from the BNST onto accumbal parvalbumin neurons controls anxiety. Molecular Psychiatry. 2020; In Press. [DOI:10.1038/s41380-020-08163] [PMID]

4. Cueto-Escobedo J, Andrade-Soto J, Lima-Maximino $M$, Maximino C, Hernбndez-Lypez F, Rodrnguez-Land JF. Involvement of GABAergic system in the antidepressant-like effects of chrysin (5, 7-dihydroxyflavone) in ovariectomized rats in the forced swim test: comparison with neurosteroids. Behavioural Brain Research. 2020; 386:112590. [DOI: 10.1016/j.bbr.2020.112590] [PMID]

5. Mohammadi S, Oryan S, Komaki A, Eidi A, Zarei M. Effects of hippocampal microinjection of irisin, an exercise-induced myokine, on spatial and passive avoidance learning and memory in male rats. International Journal of Peptide Research and Therapeutics. 2020; 26(1): 357-67.

6. Mahmoudi M, Shahidi S, Golmohammadi H, Mohammadi S. The effect of Echium amoenum hydro-alcoholic extract on blood glucose level, lipid profile and lipoproteins in Streptozotocin-induced diabetic male rats. Journal of Zanjan University of Medical Sciences and Health Services. 2015; 23(97):72-81.

7. Asgari Nematian $M$, Yaghmaei $P$, Mohammadi $S$. Assessment of the antinociceptive, antiinflammatory and acute toxicity effects of Ducrosia anethifolia essential oil in mice. Sci J Kurdistan Univ Med Sci. 2017; 22:74-84.

8. Fallahzadeh AR, Zarei $M$, Mohammadi S. Preliminary phytochemical screening, analgesic and anti-inflammatory effect of Eryngium pyramidale Boiss. \& Husson essential oil in male rat. Entomology and Applied Science Letters. 2016; 3(5):140-7.

9. Calderon-Montano JM, Burgos-Moryn E, Pŭrez-Guerrero C, Lypez-L6zaro M. A review on the dietary flavonoid kaempferol. Mini Reviews in Medicinal Chemistry. 2011; 11(4):298-344. [DOI:10.2174/138955711795305335] [PMID]
10. Chen AY, Chen YC. A review of the dietary flavonoid, kaempferol on human health and cancer chemoprevention. Food Chemistry. 2013; 138(4):2099-107. [DOI:10.1016/ j.foodchem.2012.11.139] [PMID] [PMCID]

11. Moore W, Alkhalidy H, Zhou K, Liu D. Flavonol kaempferol improves glucose homeostasis via suppressing hepatic glucose production and enhancing insulin sensitivity in diabetic mice. The FASEB Journal. 2017; 31(1 Suppl):64652. [DOI:10.1096/fasebj.31.1 supplement.646.52]

12. Golshani Y, Mohammadi S. Evaluation of antinociceptive effect of methanolic extract of Lallemantia iberica in adult male rats. Armaghane danesh. 2015; 19(12):1058-68.

13. Zarei M, Mohammadi S, Jabbari S, Shahidi S. Intracerebroventricular microinjection of kaempferol on memory retention of passive avoidance learning in rats: involvement of cholinergic mechanism (s). International Journal of Neuroscience. 2019; 129(12):1203-12. [DOl: 10.1080/00207454.2019.1653867] [PMID]

14. Grundmann O, Nakajima JI, Kamata K, Seo S, Butterweck V. Kaempferol from the leaves of Apocynum venetum possesses anxiolytic activities in the elevated plus maze test in mice. Phytomedicine. 2009; 16(4):295-302. [DOI:10.1016/j.phymed.2008.12.020] [PMID]

15. Aguirre-Hernбndez E, Gonz6lez-Trujano ME, Terrazas T, Santoyo JH, Guevara-Fefer P. Anxiolytic and sedative-like effects of flavonoids from Tilia americana var. mexicana: GABAergic and serotonergic participation. Salud Mental. 2016; 39(1):37-46. [DOI:10.17711/SM.0185-3325.2015.066]

16. Gastyn MS, Cid MP, Salvatierra NA. Bicuculline, a GABAAreceptor antagonist, blocked HPA axis activation induced by ghrelin under an acute stress. Behavioural Brain Research. 2017: 320:464-72. [DOI:10.1016/j.bbr.2016.10.035] [PMID]

17. Eidi M, Zarrindast MR, Eidi A, Oryan S, Parivar K. Effects of histamine and cholinergic systems on memory retention of passive avoidance learning in rats. European Journal of Pharmacology. 2003; 465(1-2):91-6. [DOI:10.1016/s00142999(03)01440-7] [PMID]

18. Golshani Y, Mohammadi S. Effects of Rhus Coriaria essentia oil on depression and anxiety in male rats. Feyz Journal. 2019; 23(5):476-84.

19. Paxinos G, Watson C. The rat brain in stereotaxic coordinates in stereotaxic coordinates. Amsterdam, Netherlands: Elsevier; 2007.

20. Shekarian M, Komaki A, Shahidi S, Sarihi A, Salehi I, Raoufi $\mathrm{S}$. The protective and therapeutic effects of vinpocetine, a PDE1 inhibitor, on oxidative stress and learning and memory impairment induced by an intracerebroventricular (ICV) injection of amyloid beta $(\mathrm{a} \beta)$ peptide. Behavioural Brain Research. 2020; 383:112512. [DOI:10.1016/j.bbr. 2020.112512] [PMID]

21. Mohammadi S, Oryan S, Komaki A, Eidi A, Zarei M. Effects of intra-dentate gyrus microinjection of myokine irisin on long-term potentiation in male rats. Arquivos de Neuropsiquiatria. 2019; 77(12):881-7. [DOI:10.1590/0004282X20190184] [PMID]

22. Shahidi S, Hashemi-Firouzi N, Mahmoodi M. Coadministration of fluoxetine and Sildenafil has benefits in anxiety behavior in mice. Neurochemical Journal. 2013; 7(1):34-8. [DOI:10.1134/S181971241301008X]

23. Zarei M, Ahmadimoghaddam D, Mohammadi S. Artemisia biennis Willd: Anti-Nociceptive effects and possible mechanisms of action. Journal of Ethnopharmacology. 2021; 268: 113604. [DOI: 10.1016/j.jep.2020.113604]

24. Mahmoodi M, Mohammadi S, Enayati F. Evaluation of the antinociceptive effect of hydroalcoholic extract of Potentilla reptans L. in the adult male rat. SSU_Journals. 2016; 24(3):201-10.

25. Zarrindast MR, Rostami P, Sadeghi-Hariri M. GABAA but not $G A B A B$ receptor stimulation induces antianxiety profile in rats. Pharmacology Biochemistry and Behavior. 2001; 69112):9-15. [DOI:10.1016/s0091-3057(01)00518-4] [PMID]

26. Lawton CA, Kallai J. Gender differences in wayfinding strategies and anxiety about wayfinding: A cross-cultural comparison. Sex Roles. 2002; 47(9-10):389-401. [DOI:10.1023/A:1021668724970]

27. Zhang LM, Yao JZ, Li Y, Li K, Chen HX, Zhang YZ, et al. Anxiolytic effects of flavonoids in animal models of posttraumatic stress disorder. Evidence-Based Complementary 
and Alternative Medicine. 2012; 2012:623753. [DOI: 10.1155/2012/623753] [PMID] [PMCID]

28. Lv YW, Guo JY, Liu Y, Liu J, Wu MX, He YS, et al. Advanced in studies on anxiolytic effects of natural flavonoids. Zhongguo Zhong Yao Za Zhi. 2016; 41(1):3844. [DOI:10.4268/cjcmm20160108] [PMID]

29. Emamghoreishi M, Khasaki M, Aazam MF. Coriandrum sativum: evaluation of its anxiolytic effect in the elevated plus-maze. Journal of Ethnopharmacology. 2005; 96(3):36570. [DOI:10.1016/j.jep.2004.06.022] [PMID]

30. de Carvalho RSM, Duarte FS, de Lima TCM. Involvement of GABAergic non-benzodiazepine sites in the anxiolytic-like and sedative effects of the flavonoid baicalein in mice. Behavioural Brain Research. 2011; 221(1):75-82. [DOI:10.1016/j.bbr.2011.02.038] [PMID]

31. Wolfman C, Viola H, Paladini A, Dajas F, Medina JH.
Possible anxiolytic effects of chrysin, a central benzodiazepine receptor ligand isolated from Passiflora coerulea. Pharmacology Biochemistry and Behavior. 1994; 47(1):1-4. [DOI:10.1016/0091-3057(94)90103-1] [PMID]

32. Rosa JM, Dafre AL, Rodrigues ALS. Antidepressant-like responses in the forced swimming test elicited by glutathione and redox modulation. Behavioural Brain Research. 2013; 253:165-72. [DOI:10.1016/j.bbr.2013.07.009] [PMID]

33. Garcha-Mediavilla V, Crespo I, Collado PS, Esteller A S6nchez-Campos S, Tucyn MJ, et al. The anti-inflammatory flavones quercetin and kaempferol cause inhibition of inducible nitric oxide synthase, cyclooxygenase-2 and reactive C-protein, and down-regulation of the nuclear factor kappaB pathway in Chang Liver cells. European Journal of Pharmacology. 2007; 557(2-3):221-9. [DOI: 10.1016/j.ejphar.2006.11.014] [PMID] 